\title{
Frey Syndrome-An Underreported Complication to Closed Treatment of Mandibular Condyle Fracture? Case Report and Literature Review
}

\author{
Tue W. Kragstrup, MD, * Jennifer Christensen, DDS, $\dagger$ \\ Karin Fejerskov, DDS, $\neq$ and Ann Wenzel, PhD, DrOdont, $\mathbb{I}$
}

Frey syndrome (auriculotemporal syndrome, gustatory sweating) is characterized by episodes of warmth, flushing, and sweating of the face in the preauricular region initiated by gustatory stimulus. ${ }^{1}$ Frey syndrome is a common complication after operations on the parotid gland and the temporomandibular joint. ${ }^{2,3}$ The most common hypothesis is that regenerating parasympathetic fibers to salivary glands connect in error with the sweat glands and subcutaneous blood vessels of the skin. The onset has usually been 12 to 18 months after surgery. The most effective treatment has been subcutaneous infiltration of botulinum toxin into the affected area. ${ }^{4}$

Fracture of the mandible is a common injury. The mandibular condyle will sustain a fracture in $10 \%$ to $40 \%$ of all mandibular fractures, and $19 \%$ of condylar fractures will be dislocated. ${ }^{5,6}$ The treatment of condylar fractures is still under evaluation, and closed treatment with maxillomandibular fixation has frequently been selected. ${ }^{7}$

Few reports exist on the development of Frey syndrome after acute mechanical trauma to the jaws, and

\footnotetext{
${ }^{*}$ Medical Intern, Department of Orthopedic Surgery, Bispebjerg Hospital, University of Copenhagen, Copenhagen, Denmark.

$\dagger \mathrm{PhD}$ Student, Departments of Oral Radiology and Oral and Maxillofacial Surgery and Oral Pathology, Aarhus University School of Dentistry, Aarhus, Denmark.

‡Clinical Teacher, Department of Clinical Oral Physiology, Aarhus University School of Dentistry, Aarhus, Denmark.

§Professor, Department of Oral Radiology, Aarhus University School of Dentistry, Aarhus, Denmark.

Address correspondence and reprint requests to Dr Kragstrup: Department of Orthopedic Surgery, Bispebjerg Hospital, Bispebjerg Bakke 23, Copenhagen 2400, Denmark; e-mail: t.kragstrup@dadlnet.dk

(C) 2011 American Association of Oral and Maxillofacial Surgeons

$0278-2391 / 11 / x \times 0 x-0 \$ 36.00 / 0$

doi:10.1016/j.joms.2010.12.033
}

the frequency after closed treatment of mandibular condyle fracture is unknown.

\section{Case Report}

A 23-year-old woman was referred to the Aarhus University School of Dentistry for an insurance examination after a bicycle accident 18 months earlier. She had had fractures of several teeth, the mandibular body between the lower right lateral and central incisor, the right coronoid process, and both condyles. The right condylar head had been displaced medially (Fig 1A,B). The patient had undergone open reduction and internal fixation of the symphysis and closed treatment with intermaxillary fixation of the coronoid and condylar fractures. She complained of hypoesthesia in the preauricular region and the cheek on the right side and fatigue and pain of both temporomandibular joints. Clinical examination by a temporomandibular joint specialist revealed tender masseter and temporal muscles in both sides and a reduced mouth opening. These problems were all well-known complications to mandibular fractures. The patient had also during the previous couple of months experienced episodes of sweating, blushing, and warmth in the preauricular region and cheek on the right side while eating. At the first clinical examination, this problem was not elicited, because the patient did not connect it to the trauma. She coincidentally confronted one of us (T.W.K.; a medical student at the time) with the problem, and he suspected Frey syndrome. At the second clinical examination some months later, clinical images were taken before and after she had eaten a sandwich. These showed flushing and sweat production at the right side (data not shown). Next, the minor starch-iodine test ${ }^{8}$ was performed, confirming sweating on the right side (Fig 2). Thermography was also performed, with the thermograms visualizing heat production. After the patient chewed the sandwich, the temperature increased on average $2.2^{\circ} \mathrm{C}$ (from $32.5^{\circ} \mathrm{C}$ to $34.7^{\circ} \mathrm{C}$ ) on the right side and only $1.1^{\circ} \mathrm{C}$ (from $32.0^{\circ} \mathrm{C}$ to $33.1^{\circ} \mathrm{C}$ ) on the left side (Fig 3). The patient was diagnosed with Frey syndrome as a complication of the medially dislocated mandibular condyle fracture managed by closed treatment. The patient was pleased by the explanation of her symptoms and did not want any treatment.

\section{Literature Review}

One prospective study and 10 case reports describing the development of Frey syndrome after 

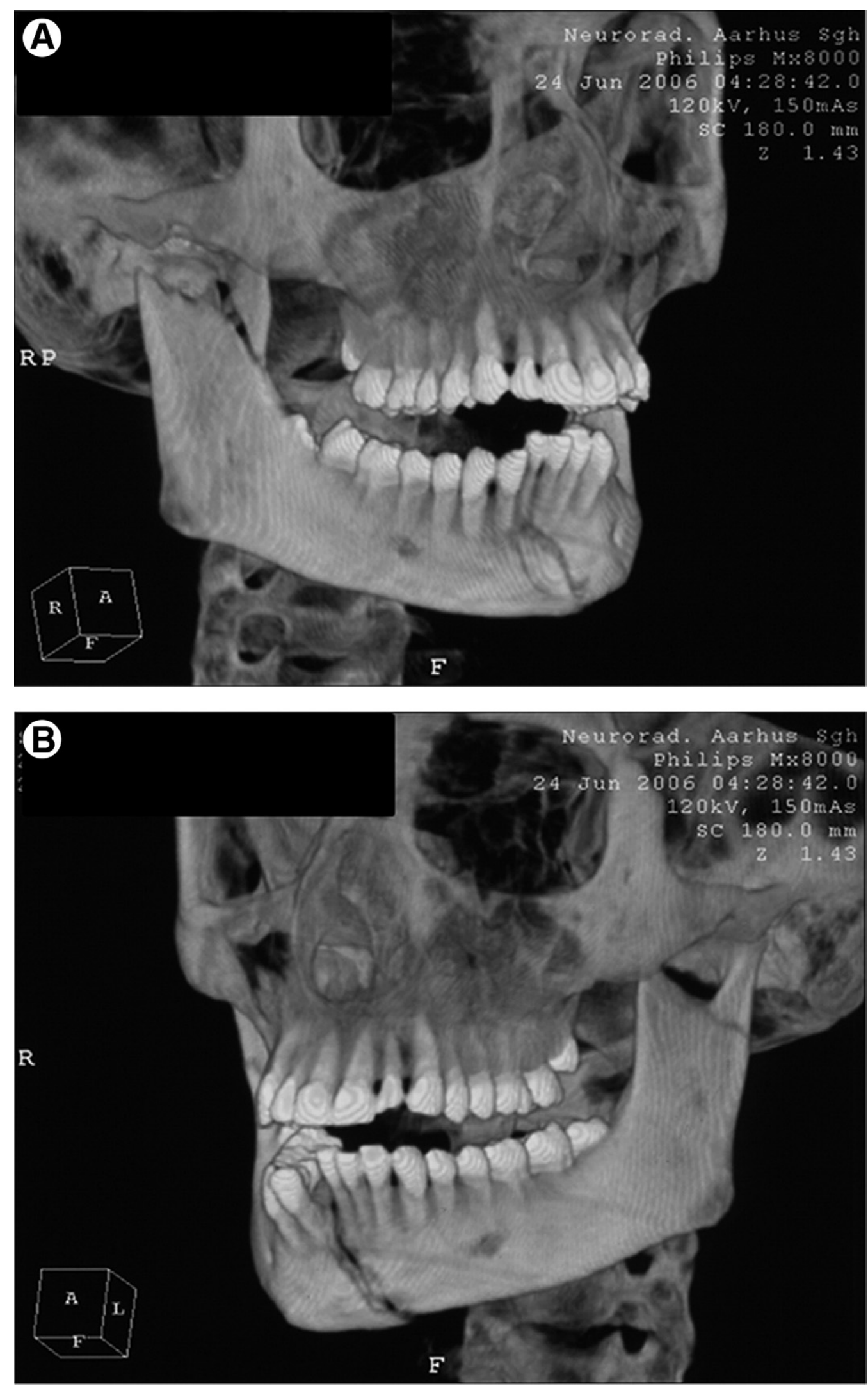

FIGURE 1. Three-dimensional CT scan reconstruction of $A$, right side and $B$, left side showing fractures of several teeth, mandibular body between the lower right lateral and central incisor, right coronoid process, left condyle without dislocation, and right condyle with medial dislocation. 


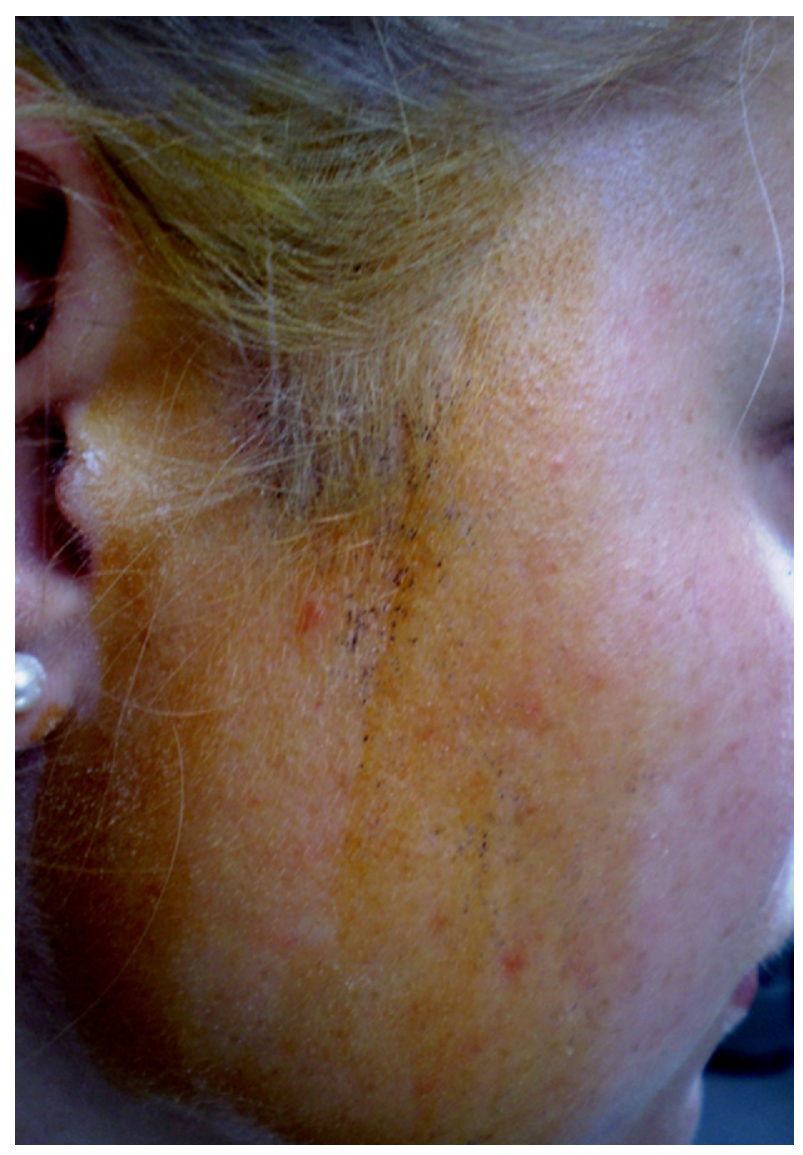

FIGURE 2. Clinical image showing minor starch-iodine test. Black dots indicate sweating.

Kragstrup et al. Frey Syndrome. J Oral Maxillofac Surg 2011.

closed treatment of mandibular condyle fractures were found in the period from 1969 to 2010 using the search criteria in PubMed: "Frey syndrome" combined with "mandibular fracture" or "jaw trauma." These reports were thoroughly studied.

The single prospective study was published in 1977 by Schmidseder and Scheunemann, ${ }^{9}$ who reported 2 cases of Frey syndrome $(0.8 \%)$ in 237 fractures of the mandibular condyle managed by closed treatment from 1971 to 1975 . All 10 case reports described patients with Frey syndrome that developed after closed treatment of mandibular condyle fractures. ${ }^{10-18}$ Table 1 lists the patient characteristics from each case report. In 9 of the 10 cases, the fractures had resulted from traffic accidents or falls from above ground level. The mandibular condyle was dislocated in 6 cases, and 9 patients had more than 1 mandibular fracture site. In 5 of the 10 cases, the patient had had altered sensibility in the affected area. The latency period before the onset of symptoms ranged from 2 months to 2 years, and only 1 of the 10 patients had had spontaneous remission.

\section{Discussion}

The incidence of Frey syndrome after closed treatment of a condylar fracture in the 1 prospective study was almost $1 \% .{ }^{9}$ Considering the relatively high frequency of mandibular condyle fractures, it is noteworthy that only 10 cases have been reported in the past 4 decades. This could suggest that the complication might be underreported. Just as occurred in the present patient, the explanations could be that the patient has not connected the symptoms to the trauma or that the symptoms or diagnosis were unknown to the clinicians examining the patient. Frey syndrome might be known to otolaryngologists; however, many patients will primarily be examined by physicians or oral surgeons and radiologists who might not be acquainted with the characteristic symptoms. Also, the long latency and the peculiar association between eating and the development of symptoms might make it difficult for patients to explain the symptoms. It is therefore essential that oral surgeons, temporomandibular joint specialists, and dental-maxillofacial radiologists consider Frey syndrome when examining patients with previous mandibular condyle fracture managed by closed treatment.

The anatomy and pathology of Frey syndrome after closed treatment of condylar fracture has been previously reviewed. ${ }^{1,17,19}$ Frey syndrome develops because of nerve injury. The nerve in question is thought to be the auriculotemporal nerve, which consists of parasympathetic fibers to the parotid gland, sympathetic fibers to the sweat glands and subcutaneous vessels of the skin, and sensory fibers to the skin in the preauricular area. The auriculotemporal nerve is a branch of the mandibular division of the trigeminal nerve and passes just posterior to the mandibular condyle. Injury to the auriculotemporal nerve by a fractured and dislocated condyle is thought to be the mechanism leading to the autonomic neuropathies of Frey syndrome after closed treatment of condylar fractures. The gustatory sweating of Frey syndrome can be explained by 2 hypotheses. The most common hypothesis is that the regenerating parasympathetic fibers to salivary glands connect in error with the sweat glands. The other hypothesis is that the sweat glands develop an increased sensitivity after degeneration of sympathetic fibers and are then stimulated by acetylcholine released from adjacent parasympathetic fibers in the parotid gland. The gustatory vasodilation of Frey syndrome causing blushing and warmth is more difficult to elucidate. However, it has mostly been hypothesized to be caused by the misdirected regeneration of parasympathetic fibers to the subcutaneous blood vessels. 

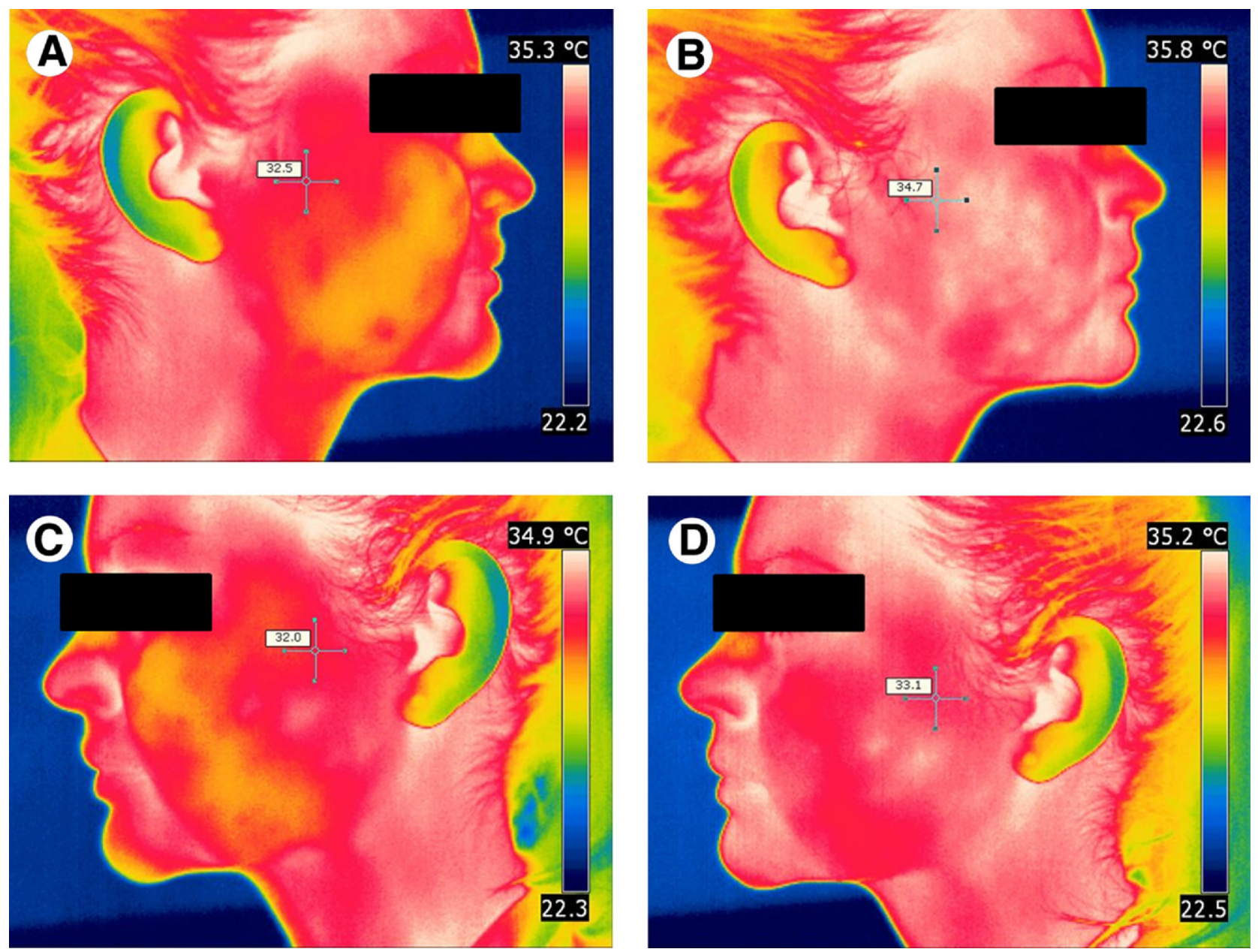

FIGURE 3. Thermograms showing mean temperature at affected region $A$, before and $B$, after patient chewed a sandwich and at the unaffected region $C$, before and $D$, after patient chewed a sandwich. White indicates areas with highest temperature.

Kragstrup et al. Frey Syndrome. J Oral Maxillofac Surg 2011.

Under these circumstances, gustatory stimuli will lead, not only to stimulation of the parotid gland, but also to stimulation of the sweat glands and subcutaneous blood vessels. The symptoms of these autonomic neuropathies are episodes of warmth, flushing, and sweating of the face in the preauricular region initiated by gustatory stimulus. The changed sensibility associated with Frey syndrome can be explained by the injury to the auriculotemporal nerve or smaller nerves in the area.

In the present case, and in most of the previous case reports, Frey syndrome after closed treatment of a mandibular fracture developed after a traffic accident. Another characteristic was the presence of more than 1 fracture of the mandible. This could suggest that injury of the auriculotemporal nerve requires trauma with a considerable impact. In more than one half of the cases, the mandibular condyle was dislocated. Dislocation of the condyle could also be a risk factor for developing Frey syndrome, considering the anatomy of the auriculotemporal nerve.
Altered sensibility was also present in one half of the cases and in our patient and might also be associated with the development of Frey syndrome, because this would indicate injury to the auriculotemporal nerve. The difference in the latency period could be explained by the different hypotheses of the pathology of Frey syndrome. ${ }^{17}$ The theory of regenerating nerves explains well the cases of the syndrome developing after 6 months or longer. The hypothesis of degenerating nerves could explain the cases with a faster onset of symptoms. The only patient with spontaneous remission had had a fast onset, which might suggest that late onset predicts a worse prognosis.

The diagnosis of Frey syndrome is based on the characteristic symptoms. In addition, the minor starch-iodine test is a sensitive diagnostic tool. ${ }^{8}$ In the present case, thermography displayed the heat production characteristic of Frey syndrome. Thermography has previously been suggested as a valid method to document the temperature differences between the 2 sides of the face 
Table 1. PATIENT CHARACTERISTICS FROM PREVIOUS CASE REPORTS

\begin{tabular}{|c|c|c|c|c|c|c|}
\hline Investigator & Trauma & Other Fractures & $\begin{array}{l}\text { Condylar } \\
\text { Dislocation }\end{array}$ & $\begin{array}{l}\text { Changed } \\
\text { Sensibility }\end{array}$ & Latency & Course \\
\hline Laws et $\mathrm{al}^{12}$ & $\begin{array}{l}\text { Fall from a } \\
\text { scaffold }\end{array}$ & Ascending ramus & $\begin{array}{l}\text { Medial } \\
\quad \text { dislocation }\end{array}$ & $\begin{array}{l}\text { Hypersensitivity in } \\
\text { the preauricular } \\
\text { region }\end{array}$ & $6 \mathrm{mo}$ & $\begin{array}{l}\text { Remission after resection } \\
\text { of the } \\
\text { temporomandibular } \\
\text { nerve }\end{array}$ \\
\hline Laws et $\mathrm{al}^{12}$ & $\begin{array}{l}\text { Bicycle } \\
\text { accident }\end{array}$ & None & None & None & $>6 \mathrm{yr}$ & Chronic \\
\hline Martis et $\mathrm{al}^{13}$ & $\begin{array}{l}\text { Car } \\
\text { accident }\end{array}$ & $\begin{array}{l}\text { Body, zygomatic } \\
\text { arch }\end{array}$ & None & $\begin{array}{l}\text { Hypersensitivity in } \\
\text { preauricular } \\
\text { region }\end{array}$ & $1 \mathrm{mo}$ & Spontaneous remission \\
\hline Storrs et $\mathrm{al}^{16}$ & $\begin{array}{l}\text { Traffic } \\
\text { accident }\end{array}$ & $\begin{array}{l}\text { Symphysis, } \\
\text { angle, other } \\
\text { condyle }\end{array}$ & $\begin{array}{l}\text { Posterior } \\
\text { dislocation }\end{array}$ & $\begin{array}{l}\text { Paresthesia in } \\
\text { front of ear }\end{array}$ & $2 \mathrm{yr}$ & Chronic \\
\hline Olson et $\mathrm{al}^{15}$ & $\begin{array}{l}\text { Motorcycle } \\
\text { accident }\end{array}$ & $\begin{array}{l}\text { Symphysis, } \\
\text { coronoid, } \\
\text { other condyle }\end{array}$ & None & None & $3 \mathrm{mo}$ & Chronic \\
\hline Goodman et al ${ }^{11}$ & $\begin{array}{c}\text { Motorcycle } \\
\text { accident }\end{array}$ & $\begin{array}{c}\text { Parasymphyseal, } \\
\text { other condyle }\end{array}$ & Not stated & None & Years & Not stated \\
\hline Zoller et al ${ }^{17}$ & $\begin{array}{l}\text { Car } \\
\text { accident }\end{array}$ & $\begin{array}{l}\text { Symphysis, } \\
\text { midface, skull } \\
\text { base }\end{array}$ & Medial & $\begin{array}{l}\text { Hypoesthesia in } \\
\text { preauricular } \\
\text { region }\end{array}$ & $2-3 \mathrm{mo}$ & Not stated \\
\hline Dhaif et $\mathrm{al}^{1}$ & $\begin{array}{l}\text { Traffic } \\
\text { accident }\end{array}$ & Parasymphyseal & Dislocated & None & $3 \mathrm{mo}$ & Not stated \\
\hline Mellor et $\mathrm{al}^{14}$ & $\begin{array}{l}\text { Fall after } \\
\text { fainting }\end{array}$ & $\begin{array}{c}\text { Parasymphyseal, } \\
\text { other condyle }\end{array}$ & $\begin{array}{l}\text { Open through } \\
\text { auditory } \\
\text { meatus }\end{array}$ & $\begin{array}{l}\text { Paresthesia in } \\
\text { preauricular } \\
\text { region }\end{array}$ & $1 \mathrm{yr}$ & Chronic \\
\hline Gerbino et al ${ }^{10}$ & $\begin{array}{l}\text { Jump from } \\
\text { 3rd floor }\end{array}$ & $\begin{array}{l}\text { Symphysis, other } \\
\text { condyle, Le } \\
\text { Fort I }\end{array}$ & $\begin{array}{l}\text { Medial } \\
\text { dislocation }\end{array}$ & None & 6-7 mo & Chronic \\
\hline
\end{tabular}

Kragstrup et al. Frey Syndrome. J Oral Maxillofac Surg 2011.

(when only 1 side is affected). ${ }^{20}$ This can be an aid in insurance cases, when the degree of permanent injury must be reported.

The treatment of Frey syndrome has been previously reviewed. ${ }^{4}$ The condition can cause considerable social embarrassment and social incapacity because of the profuse flushing and sweating when eating, and the diagnosis should have an effect on the insurance benefits for the patient. Importantly, however, only a few patients with Frey syndrome will need treatment other than an explanation of the condition and reassurance. If treatment is required, the most effective treatment has been subcutaneous infiltration of botulinum toxin to the affected area.

In conclusion, the present case report has described the development of Frey syndrome after a dislocated mandibular condyle fracture managed by closed treatment. The findings from the literature review suggest that the complication might be underreported. The risk factors seem to be trauma with a considerable impact, more than 1 mandibular fracture site, dislocation of the mandibular condyle, and altered sensibility in the preauricular region. The minor starch-iodine test and thermographic imaging can supplement the clinical examination.

\section{Acknowledgment}

Professor Robert Gniadecki and Heidi Larsen from the Department of Dermatology, Bispebjerg Hospital, Denmark are thanked for helping with the minor starch-iodine test.

\section{References}

1. Frey: Le syndrome du nerf auriculo-temporal. Rev Neurol 2:97, 1923

2. Langdon JD: Complications of parotid gland surgery. J Maxillofac Surg 12:225, 1984

3. Swanson KS, Laskin DM, Campbell RL: Auriculotemporal syndrome following the preauricular approach to temporomandibular joint surgery. J Oral Maxillofac Surg 49:680, 1991

4. de Bree R, van der Waal I, Leemans CR: Management of Frey syndrome. Head Neck 29:773, 2007

5. Sawazaki R, Lima-Junior SM, Asprino L, et al: Incidence and patterns of mandibular condyle fractures. J Oral Maxillofac Surg $68: 1252,2010$

6. Zachariades N, Mezitis M, Mourouzis C, et al: Fractures of the mandibular condyle: A review of 466 cases. Literature review, reflections on treatment and proposals. J Craniomaxillofac Surg 34:421, 2006

7. Park JM, Jang YW, Kim SG, et al: Comparative study of the prognosis of an extracorporeal reduction and a closed treatment in mandibular condyle head and/or neck fractures. J Oral Maxillofac Surg 68:2986, 2010

8. Hexsel D, Rodrigues TC, Soirefmann M, et al: Recommendations for performing and evaluating the results of the minor test according to a sweating intensity visual scale. Dermatol Surg 36:120, 2010 
9. Schmidseder R, Scheunemann H: Nerve injury in fractures of the condylar neck. J Maxillofac Surg 5:186, 1977

10. Dhaif G, Kuriakose S, Sleeman D, et al: Frey's syndrome after fracture of the mandibular condyle. Oral Surg Oral Med Oral Pathol Oral Radiol Endod 80:2, 1995

11. Gerbino G, Roccia F, Grosso M, et al: Pseudoaneurysm of the internal maxillary artery and Frey's syndrome after blunt facial trauma. J Oral Maxillofac Surg 55:1485, 1997

12. Goodman RS: Frey's syndrome: Secondary to condylar fracture. Laryngoscope 96:1397, 1986

13. Laws IM: Two unusual complications of fractured condyles. Br J Oral Surg 5:51, 1967

14. Martis C, Athanassiades S: Auriculotemporal syndrome (Frey's syndrome), secondary to fracture of the mandibular condyle. Plast Reconstr Surg 44:603, 1969
15. Mellor TK, Shaw RJ: Frey's syndrome following fracture of the mandibular condyle: Case report and literature review. Injury 27:359, 1996

16. Olson RE, Walters CL, Powell WJ: Gustatory sweating caused by blunt trauma. J Oral Surg 35:306, 1977

17. Storrs TJ: A variation of the auriculotemporal syndrome. Br J Oral Surg 11:236, 1974

18. Zoller J, Herrmann A, Maier H: Frey's syndrome secondary to a subcondylar fracture. Otolaryngol Head Neck Surg 108:751, 1993

19. Harper KE, Spielvogel RL: Frey's syndrome. Int J Dermatol 25:524, 1986

20. Isogai N, Kamiishi H: Application of medical thermography to the diagnosis of Frey's syndrome. Head Neck 19:143, 1997 